\title{
Treating Iron Deficiency Anemia
}

\section{Jagdish Chandra ${ }^{1}$}

Received: 18 October 2019 / Accepted: 23 October 2019/Published online: 11 November 2019

(C) Dr. K C Chaudhuri Foundation 2019

Even at the present time, iron deficiency anemia (IDA) is highly prevalent among Indian children. According to 4th National Family Health Survey (NFHS-4), 58.6\% children aged 6-59 mo are anemic [1]. Inherent to IDA (or iron deficiency without anemia) is its negative impact on cognitive functions in children. Young children are more vulnerable as cognitive impairment resulting from IDA may be irreversible in them. More recently, there is a focus on economic impact that the countries have on account of iron deficiency. Plessow et al. have estimated that in India IDA between 6 and 59 mo in annual birth cohort amounts to production losses of 24,001 million USD which is equal to $1.3 \%$ of gross domestic product [2]. To minimize these and other adverse effects, it is prudent to identify and treat IDA adequately.

Treatment of IDA requires iron supplementation over a long period of time; 2-3 mo after desired $\mathrm{Hb}$ level is achieved which may mean 5-6 mo total duration of therapy. Therefore, the iron salts used to treat IDA should be effective, free of adverse effects and inexpensive as in developing countries drug affordability may negatively influence compliance.

As all iron needs to be changed to ferrous forms for absorption, ferrous salts are traditionally recommended [3, 4]. In this issue of journal, Patil et al. have compared ferrous ascorbate (FA) and iron polymaltose complex (IPC) for treating IDA in children [5]. With a $6 \mathrm{mg} / \mathrm{kg}$ daily dose, authors have demonstrated significant improvement in $\mathrm{Hb}$ at $12 \mathrm{wk}$ compared to baseline in both the groups ( $\mathrm{Hb}$ rise $4.88 \pm 1.28 \mathrm{~g} / \mathrm{dl}$ with FA and $3.33 \pm 1.33 \mathrm{~g} / \mathrm{dl}$ with IPC). However, the Hb rise with FA was significantly higher compared to that with IPC $(p<$ 0.001). Yewale and Dewan also reported better efficacy of FA compared to colloidal iron preparation. Using $3 \mathrm{mg} / \mathrm{kg}$ dose, they observed higher mean $\mathrm{Hb}$ rise at $12 \mathrm{wk}$ intervention with FA compared to colloidal iron $(3.59 \pm 1.67 \mathrm{~g} / \mathrm{dl}$ vs. 2.43 $\pm 1.73 \mathrm{~g} / \mathrm{dl} ; P<0.01)[6]$.

Jagdish Chandra

jchandra55@gmail.com

1 Department of Pediatrics, LHMC and Associated KSCH, New Delhi, India
Higher dose probably is neither necessary nor offers any extra advantage. Many expert groups and texts have recommended $3 \mathrm{mg} / \mathrm{kg}$ dose for managing IDA in children [7]. The difference in $\mathrm{Hb}$ rise with $6 \mathrm{mg}$ doses in the present study with $3 \mathrm{mg}$ in the study by Yewale and Dewan may partly be on account of lower baseline $\mathrm{Hb}$ in the present study by Patil et al. as iron absorption is dependent on iron/ $\mathrm{Hb}$ status [5, 6].

IPC, a drug which was developed and promoted as having fewer or none adverse effects has had mixed fortunes. Some studies like the present one have shown its efficacy in raising the $\mathrm{Hb}$ almost equally well compared to ferrous sulfate or other salts $[8,9]$. However, other studies have shown the response with IPC being none or poorer than the comparator salts. In a 2009 study, Bopche et al. reported IPC being inferior to ferrous sulfate with insignificant rise in $\mathrm{Hb}$ with IPC at $4 \mathrm{wk}$ compared to significant rise with ferrous sulfate. The authors also mentioned that IPC was twice as expensive as ferrous sulfate [10].

Iron salts are available in Indian market under the wide category of hematinics. A 2012 article estimated that hematinic market in India was worth Rs 900 crores at that time and growing at $15 \%$ per year $[2,11]$. The authors reviewed the iron containing preparations in India. Of the 232 oral liquid preparations available, only $33(14.22 \%)$ contained only iron salts. Rest of the preparations contained folic acid with or without other micronutrients. For treating physicians, it is important to know which preparations are the best. Cost of these preparations for providing $100 \mathrm{mg}$ elemental iron for liquid oral formulations was Rs. 1.26 to Rs. 188.44 (nearly 170 times more expensive than the most inexpensive one). Panicker et al. also have recently compared various salts for treating IDA in adults. They observed equal efficacy of the compounds but highlighted the cost of treatment for 6 mo to vary between Rs 900 to Rs 3000 with fumarate salts being cheapest (iron sulfate, IPC and AS were not included) [12]. Panchal et al. reported comparable efficacy of FA with iron sulfate. However, they also observed total cost of therapy with FA being three times more than therapy with iron sulfate [13].

In Indian market, fumarate, sulfate and other salts are readily available. As we understand, sulfate, fumarate and 
ascorbate preparations have equal efficacy, either of the first two compounds by virtue of being significantly cheaper should be the drug of choice for treating IDA. Some children may have poor tolerance of these compounds and those will be the candidates for therapy with ascorbate salts as it is considered to be better tolerated.

\section{Compliance with Ethical Standards}

\section{Conflict of Interest None}

\section{References}

1. India Fact Sheet. National Family Health Survey-4 (2015-2016). International Institute of Population Sciences, 2016.

2. Plessow R, Arora NK, Brunner B, et al. Social costs of iron deficiency anemia in 6-59-month-old children in India. PLoS One. 2015;10:e 0136581.

3. Chandra J. Iron therapy in children (Reply). Indian Pediatr. 2008;45:705-6.

4. Nagpal J, Choudhury P. Iron formulations in pediatric practice. Indian Pediatr. 2004;41:807-15.

5. Patil P, Geeverhese P, Khaire P, et al. Comparison of therapeutic efficacy of ferrous ascorbate and iron polymaltose complex in iron deficiency anemia in children: a randomized controlled trial. Indian J Pediatr. 2019. https://doi.org/10.1007/s12098-019-03068-2.

6. Yewale VN, Dewan B. Treatment of iron deficiency anemia in children: a comparative study of ferrous ascorbate and colloidal iron. Indian J Pediatr. 2013;80:385-90.

7. Ozdemir N. Iron deficiency anemia from diagnosis to treatment in children. Turk Arch Pediatr. 2015;50:11-9.

8. Yasa B, Agaoglu L, Unuvar V. Efficacy, tolerability and acceptability of iron hydroxyl polymaltose complex versus ferrous sulfate: a randomized trial in pediatric patients with iron deficiency anemia. Int J Pediatr. 2011;2011:524520.

9. Rafael BJ, Cicero RE, Dibildox MM, Sotres RD, Gutiérrez GR. Iron poymaltose complex vs. iron sulfate in the treatment of iron deficiency in infants. Rev Mex Pediatr. 2000;67:63-7.

10. Bopche AV, Dwivedi R, Mishra R, Patel GS. Ferrous sulfate versus iron polymaltose complex for treatment of iron deficiency anemia in children. Indian Pediatr. 2009;46:883-5.

11. Karelia BN, Buch JG. Analysis of hematinic formulations available in Indian market. J Pharmacol Pharmacother. 2012;3:35-8.

12. Panicker NK, Hridya A, Prabhu R. Comparison of efficacy and safety profile of oral iron formulations in patients with iron deficiency anemia. Int J Pharm Sci Rev Res. 2016;41:248-52.

13. Panchal PJ, Desai MK, Shah SP, Solanki MN. Evaluation of efficacy, safety and cost of oral and parenteral iron preparations in patients with iron deficiency anemia. J Appl Pharmaceut Sci. 2015;5:066-72.

Publisher's Note Springer Nature remains neutral with regard to jurisdictional claims in published maps and institutional affiliations. 